\title{
Economic rationale for the option of connecting reinforcing bars in the construction
}

\author{
Anna Minnullina ${ }^{1, *}$, Ruslan Minnullin ${ }^{1}$,Elena Savoskina $^{2}$, and Tatyana Shatalova ${ }^{3}$ \\ ${ }^{1}$ Industrial University of Tyumen, Volodarskogo str., 38, Tyumen, 625000, Russian Federation \\ ${ }^{2}$ Samara State Technical University, Molodogvardeyskaya street, 244, Samara, Russia \\ ${ }^{3}$ Samara State University of economics, Solovetskoi Armii str. 141, Samara, Russia
}

\begin{abstract}
The article proposes methodology for economic feasibility of choosing the option of joining reinforcing steel when installing supporting structures based on a comparative approach. To confirm the practical applicability of the proposed recommendations, a study was conducted at a large construction company operating in the Tyumen region in Russia. The obtained results confirmed the applied nature of the proposed recommendations at the design stage of the analyzed construction object and preparation of local estimates.
\end{abstract}

\section{Introduction}

Reducing the complexity of construction of monolithic reinforced concrete structures based on improving technologies and introducing modern technical solutions is one of the most important tasks facing the leadership of construction organizations [1,2].

The quality result of concrete work is influenced by preparation of formwork, installation and quality of the joints of working reinforcement, since it is the joint work of concrete and reinforcement that forms a monolithic structure, the quality of the concrete mix, method and conditions of its transportation and placement into the formwork, as well as the corresponding seal and proper maintenance concrete during curing.

Longitudinal reinforcement perceives tensile stresses and prevents formation of vertical cracks in the stretched zone of reinforced concrete structures, transverse reinforcement and clamps prevent formation of inclined cracks from emerging oblique shear stresses near the supports, and also connect the concrete of the compressed zone with the reinforcement in the stretched zone. In constructions that accept compressive forces, longitudinal reinforcement perceives a part of the load, working with concrete.

One of the technological solutions of monolithic construction in the optimization of construction production is the introduction of mechanical couplings with the longitudinal connection of reinforcement in the supporting structure [3-8]. This technology is widely used abroad, and is an alternative option for longitudinal connection of reinforcement by means of overlap, which is actively used at present. The overlap method consists in overlapping one reinforcing bar to another and bundling them with wire. The disadvantage of the overlap method is the cost overrun of reinforcing steel for each joint, which leads to

*Corresponding author: minnullinaay@yandex.ru 
an increase in material consumption, an increase in the cost of purchasing reinforcing steel and its transportation.

\section{Methods}

To assess the feasibility of overlapping reinforcing steel or the use of mechanical coupling joints for connecting reinforcing bars, it is necessary to conduct a comparative technical and economic analysis at the design stage of monolithic reinforced concrete structures $[4,8]$.

When constructing a building from monolithic reinforced concrete structures, designers take into account several types of structures: foundation slab, monolithic columns and monolithic floor slabs. Moreover, methods of connecting reinforcing bars should be taken into account, taking into account the characteristics of each design separately.

Thus, the feasibility study algorithm for choosing the method of connecting reinforcing bars in the construction of monolithic reinforced concrete structures is presented in Figure 1.

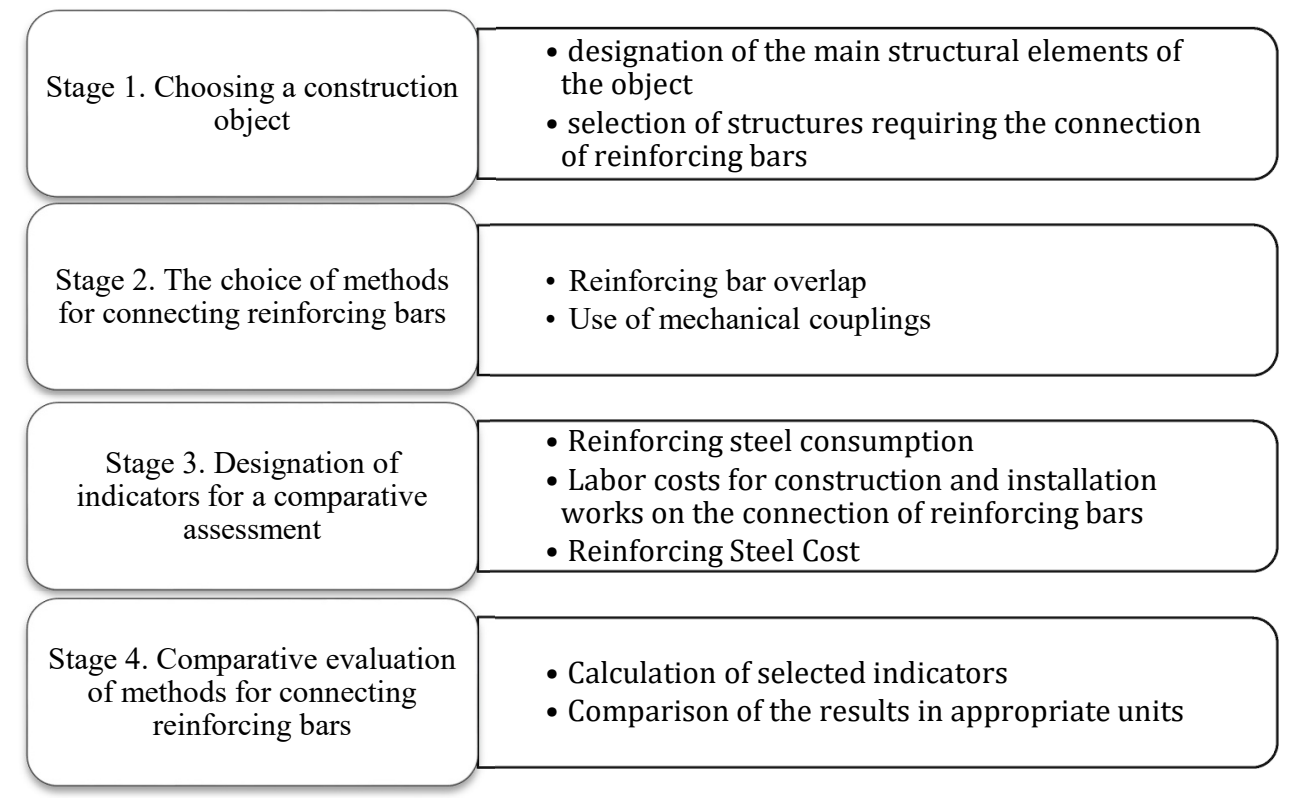

Fig. 1. Algorithm of a feasibility study for the choice of a method for connecting reinforcing bars in the construction of monolithic reinforced concrete structures.

\section{Results}

In order to test the proposed recommendations, a comparative analysis of the reinforcing bar connection was carried out at the design stage of the administrative 16storey building of a rectangular configuration with a height of $49.95 \mathrm{~m}$. The construction of this facility is planned for 2020 by construction company Art-Stroy LLC in Tyumen $[9,11]$.

The structural diagram of the building is a frame-link bezelless framework. Enclosing structures are based on the floor-to-floor overlaps and are designed so that their rigidity does not affect the rigidity of the frame. All frame elements are made of monolithic reinforced concrete. 
According to the proposed algorithm for choosing the method of joining reinforcing bars at the first stage, we will evaluate the application of the method of overlapping reinforcing bars for structures: foundation slab, monolithic columns and monolithic overlap.

1. It is customary to use a reinforced concrete foundation slab with a thickness of 1000 $\mathrm{cm}$ as the base of the building, which is reinforced with a reinforcing cage made of working reinforcing steel of a periodic profile of class A400.

Reinforcing steel with a diameter of $22 \mathrm{~mm}$ and a pitch of $150 \mathrm{~mm}$ is used for the upper and lower main reinforcement. The dimensions of the main rectangular section of the base plate in the plan are $16.5 \mathrm{mx} 37.2 \mathrm{~m}$. In accordance with the state standard of the Russian Federation (GOST 10884), the length of the measured reinforcing steel is $11.7 \mathrm{~m}$. Accordingly, in the section of the frame $16.5 \mathrm{~m}$ long 1 longitudinal connection is accepted, and on a $37.2 \mathrm{~m}$ long section 3 longitudinal connections of reinforcing steel are accepted.

With a standard connection, the overlap of reinforcing bars with each other is calculated according to the set of rules approved in the Russian Federation (SP 63.13330.2012 "Concrete and reinforced concrete structures") (table 1).

Table 1. The size of the overlap of reinforcing steel at the junction.

\begin{tabular}{|c|c|c|}
\hline $\begin{array}{c}\text { Diameter of the used reinforcing } \\
\text { bar, mm }\end{array}$ & $\begin{array}{c}\text { Weight of reinforcing } \\
\text { bar, kg / m }\end{array}$ & Overlap length, mm \\
\hline 10 & 0.617 & 300 \\
\hline 12 & 0.888 & 380 \\
\hline 16 & 1.58 & 480 \\
\hline 18 & 2 & 580 \\
\hline 22 & 2.98 & 680 \\
\hline 25 & 3.85 & 760 \\
\hline 28 & 4.83 & 860 \\
\hline 32 & 6.31 & 960 \\
\hline 36 & 7.99 & 1090 \\
\hline 40 & 9.87 & 1580 \\
\hline
\end{tabular}

The calculation of the total consumption of reinforcing steel for the production of a spatial reinforcing cage of a monolithic base plate is presented in table 2 .

Table 2. Analysis of the total consumption of reinforcing steel for the overlap joint in the production of a spatial reinforcing cage of a monolithic base plate.

\begin{tabular}{|c|l|c|}
\hline$№$ & \multicolumn{1}{|c|}{ Parameter } & Parameter value \\
\hline 1 & $\begin{array}{l}\text { Length of the base plate in plan, } \\
\text { mm }\end{array}$ & 37200 \\
\hline 2 & Width of base plate in plan, mm & 16500 \\
\hline 3 & Reinforcement pitch, mm & 11700 \\
\hline 4 & $\begin{array}{l}\text { Length of measured reinforcing } \\
\text { steel, mm }\end{array}$ & $578 \times 2=1156$ \\
\hline 5 & $\begin{array}{l}\text { Number of longitudinal joints in } \\
\text { a flat reinforcing mesh, joints }\end{array}$ & $\begin{array}{l}\text { Total number of connections of } \\
\text { reinforcing bars in the spatial }\end{array}$ \\
\hline
\end{tabular}




\begin{tabular}{|c|l|c|}
\hline & $\begin{array}{l}\text { reinforcing frame of the base } \\
\text { plate, joints }\end{array}$ & \\
\hline 7 & $\begin{array}{l}\text { Total weight of one connection } \\
\text { of reinforcing bars with a } \\
\text { diameter of } 22 \mathrm{~mm}, \mathrm{~kg}\end{array}$ & $0.68 \mathrm{~m} \times 2 \times 2.98 \mathrm{~kg} / \mathrm{m}=4.05$ \\
\hline 8 & $\begin{array}{l}\text { Total consumption of } \\
\text { reinforcing steel for an overlap } \\
\text { joint in the production of a } \\
\text { spatial reinforcing cage of a } \\
\text { monolithic base plate, } \mathrm{kg}\end{array}$ & \\
\hline
\end{tabular}

Based on the data in Table 2, the spatial reinforcing frame of the foundation slab consists of two flat reinforcing meshes; each of them contains 578 longitudinal joints of reinforcing bars with a diameter of $22 \mathrm{~mm}$.

The total consumption of reinforcing steel for overlapping joints in the production of a spatial reinforcing cage of a monolithic base plate, with a diameter of reinforcing steel of $22 \mathrm{~mm}$, will be $4681.8 \mathrm{~kg}$.

2 . The next type of structures are monolithic reinforced concrete columns with a section of $400 \times 400 \mathrm{~mm}$, which are reinforced with reinforcing steel with a diameter of $28 \mathrm{~mm}$ of class A - 400. 24 columns are designed on a typical floor of the building, each of which consists of 8 reinforcing steel rods.

The calculation of the total consumption of reinforcing steel for the connection by the overlap method when installing monolithic columns using the overlap method is presented in table 3 .

Table 3. Analysis of the total consumption of reinforcing steel for the connection by the overlap method when installing monolithic columns.

\begin{tabular}{|c|l|c|}
\hline № & \multicolumn{1}{|c|}{ Parameter } & Parameter value \\
\hline 1 & $\begin{array}{l}\text { Total weight of one connection } \\
\text { of reinforcing bars with a } \\
\text { diameter of 28 mm, kg }\end{array}$ & 24 columns $\times 17$ floors $=408$ columns \\
\hline 2 & Total number of columns & 408 columns $\times 8$ joints $\times 8.31 \frac{\mathrm{kg}}{\mathrm{m}}$ \\
3 & $\begin{array}{l}\text { Total consumption of } \\
\text { reinforcing steel for the } \\
\text { connection by the overlap } \\
\text { method when installing } \\
\text { monolithic columns, kg }\end{array}$ & $=27123.8 \mathrm{~kg}$ \\
\hline
\end{tabular}

According to the data in Table 1, total weight of one joint of reinforcing bars with a diameter of $28 \mathrm{~mm}$ will be $8.31 \mathrm{~kg}$.

Total consumption of reinforcing steel for the connection by the overlap method when installing monolithic columns will be $27123.8 \mathrm{~kg}$.

3. As a result of the design of the building, it was decided to use a reinforced concrete slab with a size of $15.9 \mathrm{~m} \times 36.6 \mathrm{~m}$ and a thickness of $200 \mathrm{~mm}$ as a floor overlap. For the upper and lower main reinforcement, working reinforcing steel with a diameter of $16 \mathrm{~mm}$ of class $\mathrm{A}-400$ and a pitch of $150 \mathrm{~mm}$ is used.

In accordance with the state standard of the Russian Federation (GOST 10884), the length of the measured reinforcing steel is $11.7 \mathrm{~m}$. Accordingly, in the section of the frame $15.9 \mathrm{~m}$ long, 1 longitudinal connection is adopted, and in the section of $36.6 \mathrm{~m}$ length 3 longitudinal reinforcement steel connections are accepted. 
Calculation of the total consumption of reinforcing steel for the overlap joint in the production of a spatial reinforcing cage of a monolithic slab is presented in table 4 .

Table 4. Analysis of total consumption of reinforcing steel for the joint by the overlap method in the production of a spatial reinforcing cage of a monolithic slab.

\begin{tabular}{|c|c|c|}
\hline № & Parameter & Parameter value \\
\hline 1 & Floor slab length in plan, $\mathrm{mm}$ & 36600 \\
\hline 2 & Width of the slab in plan, $\mathrm{mm}$ & 15900 \\
\hline 3 & Reinforcement pitch, mm & 150 \\
\hline 4 & $\begin{array}{l}\text { Length of measured } \\
\text { reinforcing steel, } \mathrm{mm}\end{array}$ & 11700 \\
\hline 5 & $\begin{array}{l}\text { The number of longitudinal } \\
\text { joints in a flat reinforcing } \\
\text { mesh, joints }\end{array}$ & $(36600 / 150 \times 1)+(15900 / 150 \times 3)=562$ \\
\hline 6 & $\begin{array}{l}\text { Total number of joints of } \\
\text { reinforcing bars in the spatial } \\
\text { reinforcing cage of a } \\
\text { monolithic slab, joints }\end{array}$ & $562 \times 2=1124$ \\
\hline 7 & $\begin{array}{l}\text { Total weight of one joint of } \\
\text { reinforcing bars with a } \\
\text { diameter of } 16 \mathrm{~mm}, \mathrm{~kg}\end{array}$ & $0.48 \mathrm{~m} \times 2 \times 1.58 \frac{\mathrm{kg}}{\mathrm{m}}=1.52$ \\
\hline 8 & $\begin{array}{l}\text { Total consumption of } \\
\text { reinforcing steel for the } \\
\text { overlap joint in the production } \\
\text { of a spatial reinforcing cage of } \\
\text { a monolithic slab, kg }\end{array}$ & $1.52 \mathrm{~kg} \times 1124$ joints $=1708.5$ \\
\hline 9 & $\begin{array}{l}\text { Total consumption of } \\
\text { reinforcing steel for } \\
\text { overlapping joints in the } \\
\text { production of a spatial } \\
\text { reinforcing cage of a } \\
\text { monolithic floor slab for all } \\
\text { floors of the facility, kg }\end{array}$ & $1708.5 \times 16=27335.7$ \\
\hline
\end{tabular}

According to table 4, total weight of one joint of reinforcing bars with a diameter of 16 $\mathrm{mm}$ will be $4.05 \mathrm{~kg}$.

Total consumption of reinforcing steel for overlapping joints in the production of a spatial reinforcing cage of a monolithic floor slab, with a reinforcing steel diameter of 16 $\mathrm{mm}$, will be $1708.5 \mathrm{~kg}$ per floor.

Thus, total consumption of reinforcing steel for joining with the overlap method when arranging the main structural elements of the object in question is $558854.1 \mathrm{~kg}$ (table 5).

Table 5. Total consumption of reinforcing steel for the production of the main structural elements of the object in question and joints by the overlap method.

\begin{tabular}{|c|l|c|c|c|}
\hline № & Structure & $\begin{array}{c}\text { Reinforcement steel } \\
\text { consumption per } \\
\text { structure, } \mathrm{kg}\end{array}$ & $\begin{array}{c}\text { Total } \\
\text { Overlap steel } \\
\text { consumption, } \\
\mathrm{kg}\end{array}$ & $\begin{array}{c}\text { consumption of } \\
\text { reinforced steel } \\
\text { with an overlap, } \\
\mathrm{kg}\end{array}$ \\
\hline 1 & Foundation slab & 50172.3 & 4681.8 & 54854.1 \\
\hline 2 & Monolithic columns & 57220.4 & 27123.8 & 84344.2 \\
\hline
\end{tabular}




\begin{tabular}{|l|l|l|l|l|}
\hline 3 & Monolithic overlap & 392320.1 & 27335.7 & 419655.8 \\
\hline 4 & Total & 499712.8 & 59141.3 & 558854.1 \\
\hline
\end{tabular}

As an alternative to connecting reinforcing bars, the use of mechanical couplings with metric threads is proposed. This type of joints in Russia during the construction of residential buildings and structures is carried out in accordance with the state standard of the Russian Federation (GOST 34278-2017).

Each company manufacturer of couplings uses a different metric thread pitch, which means that couplings from different manufacturers are not interchangeable. This circumstance should be taken into account when searching for a supplier of equipment and mechanical couplings.

At present, there are two factories on the Russian market that manufacture mechanical couplings and sell equipment for rolling threads: ZSOMS GRAD (Yekaterinburg) and LMZ ALMAZ (Lermontov).

Comparison of total consumption of reinforcing steel for each structural element of the supporting structure of the building by two methods is presented in table 6 .

Table 6. Comparative assessment of total consumption of reinforcing steel on the supporting structures of the object in question.

\begin{tabular}{|c|l|c|c|}
\hline \multirow{2}{*}{ № } & \multirow{2}{*}{ Structure } & \multicolumn{2}{|c|}{ Reinforcement steel consumption, kg } \\
\cline { 3 - 4 } & & $\begin{array}{c}\text { when overlapping } \\
\text { reinforcing bars }\end{array}$ & $\begin{array}{c}\text { when using mechanical } \\
\text { couplings }\end{array}$ \\
\hline 1 & Foundation slab & 54854.1 & 50172.3 \\
\hline 2 & Monolithic columns & 84344.2 & 57220.4 \\
\hline 3 & Monolithic overlap & 419655.8 & 392320.1 \\
\hline 4 & Total & 558854.1 & 499712.8 \\
\hline
\end{tabular}

According to table 6, consumption of reinforcing steel during longitudinal connection using mechanical couplings is most appropriate.

In addition to the consumption of reinforcing steel, it is advisable to justify the labor costs for the installation of supporting structures. This indicator is estimated on the basis of local estimates of the two considered methods for connecting reinforcing bars when the main structural elements of the object under consideration are installed.

The results of a comparative assessment of labor costs are presented in table 7.

Table 7. Comparative assessment of labor costs for construction and installation work on the production of the main structural elements of the object in question

\begin{tabular}{|c|l|c|c|}
\hline \multirow{2}{*}{ № } & \multicolumn{2}{|c|}{ Type of work } & \multicolumn{2}{|c|}{$\begin{array}{c}\text { Labor costs for the implementation of } \\
\text { construction and installation works, man-hours. }\end{array}$} \\
\cline { 3 - 4 } & & $\begin{array}{c}\text { when overlapping } \\
\text { reinforcing bars }\end{array}$ & $\begin{array}{c}\text { when using mechanical } \\
\text { couplings }\end{array}$ \\
\hline 1 & $\begin{array}{l}\text { Foundation plate } \\
\text { arrangement }\end{array}$ & 3379.4 & 3242.7 \\
\hline 2 & $\begin{array}{l}\text { Reinforced concrete } \\
\text { columns arrangement }\end{array}$ & 6982.4 & 6175.06 \\
\hline 3 & $\begin{array}{l}\text { Girderless overlaps } \\
\text { arrangement }\end{array}$ & 33559.7 & 32744.95 \\
\hline 4 & Total & 43921.5 & 42162.7 \\
\hline
\end{tabular}


Thus, the labor costs for the construction and installation work on the installation of load-bearing structures of the entire building using mechanical couplings are lower by 1758.8 people-hours.

The final and one of the most important indicator for comparing the two methods of connecting reinforcing bars in the construction of monolithic reinforced concrete structures is calculated the cost of each type of connection. This indicator is estimated taking into account the purchase of equipment and components, transportation, preparatory, construction and installation works [10].

The results of a comparative assessment of the cost of connecting reinforcing bars are presented in table 8 .

Table 8. Comparative assessment of the cost of connecting reinforcing bars

\begin{tabular}{|c|l|c|c|}
\hline \multirow{2}{*}{ № } & \multicolumn{1}{|c|}{ Structure } & \multicolumn{2}{|c|}{ The cost of connecting reinforcing bars, dollars } \\
\cline { 3 - 4 } & & $\begin{array}{c}\text { when overlapping } \\
\text { reinforcing bars }\end{array}$ & $\begin{array}{c}\text { when using mechanical } \\
\text { couplings }\end{array}$ \\
\hline 1 & $\begin{array}{l}\text { Components for construction } \\
\text { and installation work }\end{array}$ & 0 & 23613.1 \\
\hline 2 & Delivery of components & 0 & 586.6 \\
\hline 3 & Reinforcing steel delivery & 1265.8 & 1132.2 \\
\hline 4 & Reinforcing steel preparation & 0 & 2840 \\
\hline 5 & $\begin{array}{l}\text { Construction and installation } \\
\text { work }\end{array}$ & 144184.6 & 105740.4 \\
\hline 6 & Total & 145450.4 & 133912.3 \\
\hline
\end{tabular}

The cost of preparing reinforcing steel refers to the salary costs of workers performing thread rolling on reinforcing bars. The cost of construction and installation works is estimated according to local estimates.

Thus, when comparing the total cost of connecting reinforcing bars, we can conclude that the cost of construction and installation work on the construction of load-bearing structures of a building using mechanical couplings with parallel threads is lower by $\$$ $11,538.1$.

\section{Conclusions}

Thus, the most appropriate option for connecting reinforcing bars for the object under consideration is construction and installation work on the erection of load-bearing structures using mechanical couplings with parallel thread as a longitudinal connection of reinforcing steel.

However, it must be emphasized that the choice of the method of connecting reinforcing bars in monolithic reinforced concrete structures must be evaluated for each specific building object, since this depends on the following factors:

1) total volume of the spatial reinforcing cage;

2) total number of joints of reinforcing bars;

3) ability to supply the required material resources;

4) selected set of assessed indicators when comparing methods for connecting reinforcing bars. 


\section{References}

1. A. Kopytova, MATEC Web of Conferences, 106, 08056 (2017) DOI: $10.1051 /$ matecconf $/ 201710608056$

2. A. Kopytova, Exchange of intellectual property 3 (XIV), 31-37 (2015)

3. G. Gurova, V. Pavlov, L. Uvarova. New types of fittings and its welding, p. 208-211 (1982)

4. V. Degtyarev. Concrete and reinforced concrete, 6, p. 13-18 (2005)

5. V. Degtyarev. Concrete and reinforced concrete, 1, p. 2-7 (2005)

6. S. Madatyan. Reinforcement of reinforced concrete structures (2000)

7. S. Madatyan, V. Degtyarev, L. Zborovsky. Concrete and reinforced concrete, 6, p. 1214 (2001)

8. J. Cagley, R. Apple. Concrete International, P. 55-56 (1998)

9. A. Minnullina, V. Vasiliev, Determining the Supply of Material Resources for HighRise Construction: Scenario Approach. E3S Web of Conferences 33, 03060 (2018), doi:10.1051/e3sconf/20183303060

10. A.Kopytova, N. Zotkina, I. Reshetnikova, MATEC Web of Conferences, 239, 04012 (2018) DOI: $10.1051 /$ matecconf/201823904012

11. A. Minnullina. Analysis of approaches to procurement management in the organization 5, p.97-102 (2015) 